\title{
Research Ethics in Sign Language Communities ASL Translation Summary
}

\section{Raychelle Harris}

Gallaudet University

Raychelle.harris@gallaudet.edu

\section{Heidi M. MacGlaughlin}

Lamar University

Hmacglaughli@lamar.edu

\section{Donna M. Mertens}

Gallaudet University

Donna.mertens@gallaudet.edu

\section{Justin Perez}

jperezowns@gmail.com

www.justinperezvv.com

\section{Original Abstract:}

Codes of ethics exist for most professional associations whose members do research on, for, or with sign language communities. However, these ethical codes are silent regarding the need to frame research ethics from a cultural standpoint, an issue of particular salience for sign language communities. Scholars who write from the perspective of feminists, indigenous peoples, and human rights advocates have commonly expressed dissatisfaction with their lack of representation in conversations about research ethics. Members of sign language communities and their advocates can learn from others who share in this struggle and contribute much to this topic. We propose the development of sign language communities' terms of reference (SLCTR) as a means to research by, for, and with sign language communities.

\section{Short Description:}

Justin Perez provides a summary in ASL of the "Research Ethics in Sign Language Communities" article published in 2009 by Harris, Holmes, and Mertens.

Keywords: research ethics, sign language communities, SLCTR, cultural competence 


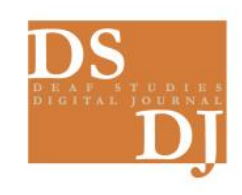

\section{ASL Summary:}

Research Ethics for Sign Language Communities.

The authors are Harris, Holmes, and Mertens. This article was published in 2009.

Why do we have research ethics for sign language communities? We have four existing legislation laws involving ethics in the United States, such as The Hatch Act (1939), National Research Act (1974), FERPA [The Family Educational Rights and Privacy Act] (1974), and National Commission for the Protection of Human Subjects in Biomedical and Behavioral Research (1978). Aren't these enough? Why is there a need for more?

Fifth, we also have the Belmont Report (1979). The Belmont Report (1979) involves humans with three principles: Respect, beneficence, and justice with a goal of no harm.

We've already told you about five different laws and reports involving research ethics. We also have research ethics within different organizations such as the APA [American Psychological Association] and CEC [Council for Exceptional Children.]

In addition to those five legislation laws and organizations that have their own research ethics, why do we need our own research ethics for sign language communities? Their ethics lack the following: the framing of research ethics from a cultural and linguistic standpoint, trust between researchers and participants in the community, and the view of research as collaborative and culturally valued.

For example, in the 1960s, Myklebust made so many claims in books and articles that many people who worked with Deaf people such as teachers, audiologists, psychologists, and school administrators believed and used his work. Examples of Myklebust's claims include the notion that Deaf people had little to no language, were more immature, emotional, had mental issues, had inferior physical coordination, were isolated, paranoid, and many more. Many people used this information in their work with Deaf children, raising the next generation of Deaf children without opportunities to thrive. That research was very unethical.

As I mentioned, many negative claims have been made about Deaf people. Now, if Deaf researchers were to lead research among hearing researchers, they would be able to challenge research about themselves that question their abilities. This is called "voice". Here's another example. If a man conducts research about women, that is unethical. It would be best for women to lead that research alongside him to ensure their voices are represented. Another example is if a white person were to conduct research about the Black community, that would also be unethical. There needs to be representation with Black researchers involved to oversee that research. Ultimately, sign language must have its own research ethics.

Pollard is a notable researcher whose recurrent work in 1992, 1994, 1996, and 2002 discussed how Sign Language communities must include its own research ethics. We pay gratitude to Pollard. 
Cultural competence on the researcher's part is a crucial disposition regarding the researcher's ability to represent reality. If they do not have it, that would be unethical. Cultural competence is necessary for a researcher to conduct research.

Those three authors determined Sign Language communities must have their own research ethics and were inspired by indigenous communities' research ethics. The authors asked and received the community's permission to borrow the idea. This led to the development of research ethics for the Sign Language communities. However, they also encourage the application and modification of their own research ethics to nonindigenous domains and each community.

The indigenous research ethics I referred to are called "indigenous terms of reference" (ITR). Now, we have Sign Language Communities Terms of Reference (SLCTR). The SLCTR consists of six principles of ethics. First, the authority for decisions made within the Sign Language communities rests with the community's members. For example, whiteness is decentralized, and the Maori from New Zealand are centered in their research. Similarly, we decentralize hearingness in the Deaf community and focus on Deaf people. Another example is research done by Deaf, for Deaf, and with Deaf people. If hearing researchers want to enter the community, they need to do it with Deaf individuals.

The second principle is that investigators should acknowledge that Sign Language community members have the right to have those things that they value and to be fully involved. An example is publishing bilingual publications with both Sign Language and English. Another example is not confirming to prevailing academic genres based on hearing ways, creating liberating research with Deaf ways of doing research.

The third principle is that investigators should take into account the many worldviews of the Sign Language communities in all negotiations or dealings. Ultimately, the decision belongs to members of the signing communities. Here are two examples. First, rather than hierarchal research teams with a hearing person on top, they should be structured as horizontal research teams as equals. Second, participants should become researchers or co-researchers to foster scholarship dialogues.

The fourth principle shares that investigators should recognize the diverse experiences and understandings, including the higher risk of confidentiality breaches for any small community, the need to communicate all names of the research team in advance, and the need of video documentation. With video documentation, how can those participants' anonymity be protected?

The fifth principle is that investigators should ensure that any process of validation must take in account the SLCRT before any decisions are made. Deaf experience must be the center of research. Sign language communities should have guidance or joint control of research projects done on sign language and Deaf people. Ownership rests with sign language and Deaf people, and they must not be exploited.

The sixth principle is that in negotiations and agreements among researchers, Deaf researchers should lead the process within their own communities with similar backgrounds. For instance, 


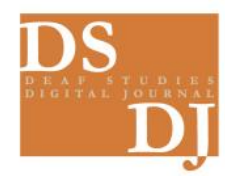

तै/2 Humanities

with DeafBlind individuals, the researcher should be DeafBlind to have a more profound impact on the community members' lives. Also, it is critical to consult all communities for their views.

In conclusion, the six principles of the SLCTR specify that research ethics require a thoughtful partnership that is jointly negotiated and constructed between researchers and participants to make the research study ethically sound. 


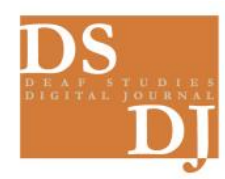

है:

\section{ORIGINAL PUBLICATION INFO}

Harris, R., Holmes, H. M., \& Mertens, D. M. (2009). Research ethics in sign language communities. Sign Language Studies, 9(2), 104-131,247. doi: https://doi.org/10.1353/sls.0.0011

\section{SUGGESTED CITATION}

Harris, R., MacGlaughlin, H.M., Mertens, D.M. \& Perez, J. (2020). Research Ethics in Sign Language Communities - ASL Translation Summary. 2020, doi: http://doi.org/10.3998/15499139.0005.017 